Comput at i onal study on si I i con oxi de pl asma enhanced chemical vapor depositi on (PECVD) process usi ng

t et $r$ aet hoxysi I ane/oxygen/ar gon/hel i um

\begin{tabular}{|l|l|}
\hline 著者 & $\begin{array}{l}\text { LI Hu, H GUCH H sashi, KAMAGUCH Sat or u, } \\
\text { SATOH Kohki, DENPOH Kazuki }\end{array}$ \\
\hline $\begin{array}{l}\text { j our nal or } \\
\text { publ i cat i on ti l l e }\end{array}$ & Japanese Journal of Appl i ed Physi cs \\
\hline vol une & 58 \\
\hline number & SE \\
\hline page r ange & SEEDO6 \\
\hline year & 2019- 05- 30 \\
\hline URL & ht t p: //hdl . handl e. net /10258/00009967 \\
\hline
\end{tabular}




\section{Computational study on silicon oxide plasma enhanced chemical vapor deposition (PECVD) process using Tetraethoxysilane/ Oxygen/ Argon/ Helium}

$\mathrm{Hu} \mathrm{Li}^{1{ }^{1, *}, \text { Hisashi Higuchi }}{ }^{1}$, Satoru Kawaguchi ${ }^{2, \dagger}$, Kohki Satoh $^{2}$ and Kazuki Denpoh ${ }^{1}$

${ }^{1}$ Tokyo Electron Technology Solutions Ltd., Nirasaki, Yamanashi 407-0192, Japan

${ }^{2}$ Division of Information and Electronic Engineering, Graduate School of Muroran Institute of Technology, Muroran, Hokkaido 050-8585, Japan

\section{Abstract}

Plasma enhanced chemical vapor deposition (PECVD) of silicon oxide $\left(\mathrm{SiO}_{2}\right)$ using tetraethoxysilane (TEOS) was investigated theoretically by developing an unprecedented plasma chemistry model in $\mathrm{TEOS} / \mathrm{O}_{2} / \mathrm{Ar} / \mathrm{He}$ gas mixture. In the gas phase reactions, a TEOS molecule is decomposed by the electron impact reaction and/or chemically oxidative reaction, forming intermediate TEOS fragments, i.e., silicon complexes. In this study, we assume that $\mathrm{SiO}$ is the main precursor that contributes to $\mathrm{SiO}_{2}$ film growth under a particular

\footnotetext{
*E-mail : hu.li@tel.com

$\dagger$ Research Fellow of Japan Society for the Promotion of Science
} 
process or simulation condition. The surface reaction was also investigated using quantum mechanical simulations with density functional theory. Based on the gas and surface reaction models, we constructed a computational plasma model for $\mathrm{SiO}_{2}$ film deposition in a PECVD process. The simulation results using CHEMKIN pro and CFD-ACE+ have shown that the neutral atomic $\mathrm{O}$ and $\mathrm{SiO}$ as well as the charged $\mathrm{O}_{2}{ }^{+}$are the dominant species to obtain a high deposition rate and uniformity. The spatial distributions of various species in the $\mathrm{TEOS} / \mathrm{O}_{2} / \mathrm{Ar} / \mathrm{He}$ gas mixture plasma were shown in the study. Uniformity of deposited film due to the change in the plasma bulk property was also discussed. 


\section{Introduction}

As the market demand for the micro-pattern formation of multi-layer structures such as 3D

NAND has been increasing rapidly, a technology for the thin film formation with high deposition rate (DR) and good uniformity under submicron or even nanometer scale patterns are highly demanded in semiconductor device manufacturing. Plasma enhanced chemical vapor deposition (PECVD) technology is widely used in the thin film deposition processes. In a PECVD process, chemically reactive species that generated in the plasma may contribute to high DR at a relatively low process temperature, whereas it requires thermally stable precursors in a conventional thermal CVD process. Therefore, this advantage offers alternative suggestions of depositing various thin films with many possible precursors in the PECVD processes.

In semiconductor fabrication processes, non-corrosive metal organic precursors have been more attractive than halide precursors, and organic silicate compounds such as tetramethoxy-silane [TMOS: $\left.\mathrm{Si}\left(\mathrm{OCH}_{3}\right)_{4}\right]$ and tetraethoxysilane [TEOS:Si( $\left.\left(\mathrm{OC}_{2} \mathrm{H}_{5}\right)_{4}\right]$ may be suitable choices for the PECVD processes of silicon oxide $\left(\mathrm{SiO}_{2}\right)$ films. TEOS has been one of the widely used gases in the industrial processes, because relatively good uniformity of a thin film can be achieved in a TEOS based PECVD process. In the industrial processes, however, we have observed that the film growth is a competition between the deposition rate 
and uniformity. Many studies [1-6] have investigated the $\mathrm{SiO}_{2} \mathrm{PECVD}$ with TEOS gas in both theoretical and experimental ways over last few decades. However, the deposition mechanism remains unknown because the gas phase and surface reactions are still not clear yet. In an earlier study, Stout and Kushner [4] have investigated surface kinetics using TEOS $/ \mathrm{O}_{2}$ chemistry and discussed the deposition mechanisms under an assumption that oxidization reaction dominantly occurs over electron impact. In another study by Holtgrave et al. [7], it was suggested that the species generated in the electron impact reactions affect the deposition properties of $\mathrm{SiO}_{2}$ film. It has been hypothesized that oxygen $(\mathrm{O})$ atoms and electrons play a great role in the gas phase reactions of TEOS decomposition. Raupp et al. [3] have focused on the role of oxygen in their PECVD model and predicted that oxygen deposition rate depends on the $\mathrm{O}$ atom density. In their model, however, dissociation of TEOS molecule by electron impact was not taken into account. Basner et al. [8] reported the cross sections for the ionization of TEOS molecule by electron impact. Neutral dissociation (ND) reactions by electron impact, which may affect the loss of electron energy and density in the plasma, may need to be considered carefully as well for the model accuracy. However, the lack of data, e.g. electron collision cross sections for the dissociation of TEOS molecule and thermodynamic properties of TEOS and its fragments, makes the difficulties on investigating the deposition mechanisms especially in a theoretical study. Recently, 
Kawaguchi et al.[9] have compiled cross sections for organic silicate compounds, such as tetramethylsilane [TMS:Si( $\left.\left(\mathrm{CH}_{3}\right)_{4}\right]$ and TEOS. In their study, electron transport coefficients were well computed by comparing with experimental data to estimate ionization coefficient in TEOS $/ \mathrm{O}_{2}$ gas mixture. In this study, we attempt to describe the gas phase and surface reactions in detail with $\mathrm{TEOS} / \mathrm{O}_{2} / \mathrm{Ar} / \mathrm{He}$ gas mixture. Based on electron collision cross sections in Ref. 9, we additionally described 18 NDs in the electron impact cross sections for TEOS and developed a plasma chemistry model in TEOS $/ \mathrm{O}_{2} / \mathrm{Ar} / \mathrm{He}$ gas mixture.

In order to seek an accurate information that could lead to solve the problems encountered in the processes, the one of the main purposes of this study is to develop a computational model for analysis of the PECVD processes and gain a further understanding of the problems in the processes as well as the deposition mechanisms. To achieve this goal, as the first step, we present a plasma chemistry model and focus on the numerical analysis on plasma behaviors in a specific plasma reactor under a specific process condition.

Briefly, the remainder of the paper is organized as follows. In Section 2, we describe the chemistry model, i.e. gas phase and surface reaction models. In Section 3, we shall introduce the plasma simulation models. We examined the chemistry model with 0 dimensional (0D) plasma simulation, and for further study we performed a 2 dimensional (2D) simulation. The results and discussions are also shown in the section. Summary of the 
conclusions are in Section 4.

\section{Reaction models in $\mathrm{TEOS} / \mathrm{O}_{2} / \mathrm{Ar} / \mathrm{He}$ plasma}

In this section, we shall describe the $\mathrm{TEOS} / \mathrm{O}_{2} / \mathrm{Ar} / \mathrm{He}$ chemistry model to be used in the plasma simulations in section 3 . The chemistry model consists of gas phase reactions and surface reactions. In the gas phase reaction model, we respectively describe the dissociation of TEOS by electron impact and oxidization of TEOS. In the surface reaction model, we investigated a surface reaction of TEOS fragments, i.e. $\mathrm{SiO}$, and a $\mathrm{SiO}_{2}$ surface. The surface reactions are performed quantum mechanically based on the density functional theory (DFT) with periodic boundary condition (PBC) using STATE (Simulation Tool for Atomic TEchnology) package $[10,11]$. In current $\mathrm{TEOS} / \mathrm{O}_{2} / \mathrm{Ar} / \mathrm{He}$ chemistry model, we have 49 species, describing 195 gas phase reactions and 25 surface reactions.

\subsection{Dissociation of TEOS by electron impact}

Table I shows the reaction formula for the dissociation of TEOS molecule by electron impact.

In this study, the electron impact reactions of TEOS for neutral dissociation and dissociative ionization have been considered carefully from earlier studies [9,12-14]. For the fragments originating from the TEOS in Table I, we speculate their geometric structures via quantum mechanical (QM) calculations based on the stoichiometry in Ref. 12. It should be noted that the geometric structures are fully optimized and chosen to obtain the corresponding potential 
energy in their DFT QM calculations with B3LYP functional [15] and 6-311+G(2d,p) basis set $[16,17]$. The activation energy that needed for dissociation may be considered as the minimum energy difference between initial and final states. More specifically, the activation energy $E$ of forming a neutral TEOS fragment $N$ from a TEOS molecule is defined using the potential energy $E_{N}$ of the neutral species, the potential energy $E_{P}$ of other products and the potential energy $E_{T E O S}$ of a TEOS molecule as $E=E_{N}+\sum E_{P}-E_{T E O S}$

Geometry optimizations for all combinations of other products, i.e. non-silicon containing species, were also performed and those which correspond to the minimum $E$ were chosen. The computed $E$ s are summarized in Table I. Based on the $E$, the branching ratios and electron cross sections for the 18 ND reactions were estimated, as shown in Fig. 1, with the classical Rice-Ramspeger-Kassel theory[18-20]. More detailed validity on the electron cross section set for TEOS is given in a separate article [21].

\subsection{Oxidization of TEOS by oxygen atom/molecule}

Figure 2 shows the oxidization reaction pathways for the TEOS decomposition. The neutral and ion species of TEOS fragments in Fig. 2 are derived from the electron impact dissociation or dissociative oxidization by the chemical reaction with an oxygen $(\mathrm{O})$ atom/molecule. In this model, as shown in Fig. 2(a), the decomposition reaction pathway for 
the neutral species of TEOS fragments by $\mathrm{O}$ atom is defined as follows. In the first step, an $\mathrm{OCH}_{2} \mathrm{CH}_{3}(\mathrm{OR})$ ligand of TEOS molecule reacts with an $\mathrm{O}$ atom to form a TEOS fragment intermediate, i.e. $\mathrm{Si}(\mathrm{OR})_{3} \mathrm{OCH}_{2} \mathrm{CH}_{2}$ or $\mathrm{Si}(\mathrm{OR})_{3} \mathrm{OCH}_{2}$, releasing a small molecular fragment, such as $\mathrm{OH}$ and $\mathrm{CH}_{2} \mathrm{O}$. In the second step, this TEOS fragment reacts with an $\mathrm{O}$ atom to form another intermediate TEOS fragment of $\mathrm{Si}(\mathrm{OR})_{3} \mathrm{OCH}_{2}$ or $\mathrm{Si}(\mathrm{OR})_{3} \mathrm{O}$. In the third step, then, the product of TEOS fragment in the second step reacts with an $\mathrm{O}$ atom, forming $\mathrm{Si}(\mathrm{OR})_{3} \mathrm{O}$ or $\mathrm{Si}(\mathrm{OR})_{3}$. In this model, the decomposition of other OR ligand occurs after complete decomposition of the previous OR ligand. TEOS molecule eventually decomposed to a $\mathrm{SiO}$ or $\mathrm{SiO}_{2}$ in this model. The decomposition reaction path for the ion species of TEOS fragments is also defined similarly as shown in Fig. 2(b). Maeda et al [22] have observed mass spectra using TEOS $/ \mathrm{O}_{2}$ plasma. In their measurements, intensity of atomic mass of 44 increased with decease in the intensity of larger atomic masses, such as 179 and 193 which correspond to the TEOS fragments, suggesting that $\mathrm{SiO}$ dominate as a silicon( $\mathrm{Si}$ ) containing species in the TEOS $/ \mathrm{O}_{2}$ plasma. The ion species of TEOS fragments, which are also generated by the electron impact, also react with an $\mathrm{O}$ atom to form another intermediate ion species of TEOS fragment, as shown in Fig. 2(b). In addition, ion species of TEOS fragment also dissociates by a negative $\mathrm{O}$ ion $\left(\mathrm{O}^{-}\right)$which is generated in the plasma with the same reaction path described in the Fig. 2(b). 
Although polymerization of TEOS fragments may occur [23] and affect the film deposition, it is not considered in current model, since the TEOS gas is sufficiently diluted with oxygen gas and inert gases in order to avoid the polymerization and/or generation of heavy particles in the PECVD processes.

\subsection{Recombination, quench and other reactions.}

Since we use TEOS $/ \mathrm{O}_{2} / \mathrm{Ar} / \mathrm{He}$ gas mixture in this study, electron impact reactions for oxygen $\left(\mathrm{O}_{2}\right)$ [24], argon (Ar) [25] and helium $(\mathrm{He})$ [26] gases are also considered. Besides, in the gas phase reaction model, we also considered recombination reactions of a positively charged ion species of TEOS fragment and $\mathrm{O}^{-}$or electron $(e)$. In the recombination reactions, the ion species is either simply neutralized with $\mathrm{O}^{-}$or $e$. For heavy particle collisions, we have considered penning ionization, charge transfer, energy transfer and quenching reactions in the gas phase reaction model. Table II summarizes the reactions used in this model.

\subsection{Surface reaction}

Table III shows the atomic concentrations measured by Rutherford backscattering spectrometry (RBS) in a $\mathrm{SiO}_{2}$ thin film which was prepared by PECVD. In RBS measurements, no signals of carbon $(\mathrm{C})$ were observed or the $\mathrm{C}$ concentration is below the detection limit. Furthermore, as will be shown in Table IV and Sec. 2, oxygen gas dominates over the others among the feeding gases, and $\mathrm{O}$ atom concentration at the surface is high. It 
is suggested that the $\mathrm{O}$ atom chemically removes the impurities on the surface[6], and a hydroxylated surface also contributes to the impurity elimination[27]. Since the amount of oxygen is large, we assumed that the OR ligands of a TEOS molecule or TEOS fragment will be sufficiently decomposed and turn to $\mathrm{SiO}$ either in the gas phase or even if when the TEOS fragments chemically absorbed on the $\mathrm{SiO}_{2}$ surface. Therefore, in current surface model, we assume that the surface reaction for the film growth is as follow:

$\mathrm{SiOH}(s)+\mathrm{SiO}(g)+\mathrm{O}(g) \rightarrow \mathrm{SiO}_{2}(b)+\mathrm{SiOH}(s)$.

Here $s$ represents a surface site, $g$ is for gas species and $b$ is for bulk. In the model, the surface is considered as a hydrogen saturated surface. In current model, we only allowed the neutral species for contributing to the film deposition. The ion species that generated in the plasma reached the surface and simply neutralized. As will be discussed below, the direct effects of ion species are something that we could not afford to ignore and therefore a subject of future work to improve the accuracy of the model.

We have investigated the surface reaction of $\mathrm{SiO}$ and a $\mathrm{SiO}_{2}$ surface using STATE with PBCs. Figure 3 shows an atomic configuration of the surface reaction model. In this surface reaction model, we used a stepped surface model. For the sake of the simplicity, detail information of the surface modeling is not shown in this article. The deposition rate (DR) equation for the $\mathrm{SiO}_{2}$ film growth in this model is given by 
$\mathrm{DR}=\eta_{s} n_{O} n_{p}$

Here $n_{O}$ and $n_{p}$ are the number densities of $\mathrm{O}$ and the precursor, i.e. $\mathrm{SiO}$, respectively. The value of sticking coefficient $\eta_{s}$ for $\mathrm{SiO}$ at the surface is 0.045 [28].

\section{Plasma simulations}

First, we examined the chemistry model described in the previous section by using a $0 \mathrm{D}$ model for a capacitively coupled plasma (CCP) with CHMKIN pro package [29]. Since gas phase reactions in CHEMKIN Pro should be specified as reaction rates in Arrhenius forms, the electron impact cross sections for TEOS, $\mathrm{O}_{2}$, Ar and He were all converted to reaction rate constants by electron swarm analysis using SWARM software[30,31]. The thermodynamic properties, i.e. heat capacity, entropy and enthalpy, for a TEOS molecule as well as all the TEOS fragments (neutral and ion species) are computed via first-principles

QM calculation based on the DFT with Gaussian09 package[32].

Figure 4 shows the $\mathrm{SiO}_{2}$ deposition rate computed using CHEMKIN Pro as well as the number densities of $\mathrm{SiO}$ and $\mathrm{O}$ species with respect to the plasma power. It has been found that the densities of $\mathrm{SiO}$ and $\mathrm{O}$ increased with increasing the plasma power. As a result, higher deposition rates were observed with increase in the amount of $\mathrm{SiO}$ and $\mathrm{O}$, suggesting that deposition rate depends on the $\mathrm{SiO}$ and $\mathrm{O}$ that are generated in the gas phase.

We have confirmed that the chemistry model works well and the results obtained in the 0D 
simulation are reasonable. Then, we incorporated the chemistry model into CFD-ACE+[33] and performed a $2 \mathrm{D}$ simulation. In the $\mathrm{CFD}-\mathrm{ACE}+$, which is a multiphysics simulator, the plasma is fully coupled with gas flow, including transportation of each species generated in the plasma, and solved simultaneously. Since electron impact cross section can be specified in the CFD-ACE+, electron impact cross section sets for TEOS, $\mathrm{O}_{2}$, $\mathrm{Ar}$, and $\mathrm{He}$ are directly used in the 2D simulation.

Figure 5 shows a schematic view of a plasma reactor for the axisymmetric 2D simulation. The TEOS $/ \mathrm{O}_{2} / \mathrm{Ar} / \mathrm{He}$ gas mixture is supplied from the showerhead which doubles as the upper electrode in Fig. 5. The wafer is placed on the dielectric stage, where a metal electrode, i.e. lower electrode, is embedded in. The gap between the upper electrode and the wafer is set to $9.2 \mathrm{~mm}$. An rf voltage was applied to the upper electrode, which is given by the following sinusoidal waveform;

$V=V_{r f} \sin (2 \pi f t)+V_{d c}$

where $V_{r f}$ is the amplitude, $f$ is the frequency, and $t$ is the time. In the present work, $V_{r f}=100 \mathrm{~V}$ and $f=13.56 \mathrm{MHz}$, respectively. The $V_{d c}$ is a self-bias voltage and it is automatically calculated in the CFD-ACE + so as to balance electron flux and ion flux for an rf cycle at the upper electrode. The lower electrode was grounded. The gray blocks on the right side represents a dielectric. The temperature of wafer stage was set at $823 \mathrm{~K}$ and the 
pressure was 4 Torr. The flow ratio of the gas mixture was TEOS : $\mathrm{O}_{2}: \mathrm{Ar}: \mathrm{He}=0.04: 0.55$ :

$0.27: 0.14$. Table 4 summarized the parameters used in the simulations.

Figure 6 shows the 2D simulation results of the spatial distribution of various species between the upper electrode and the wafer. The plotted data in Fig. 6 is the number densities of various species on the center line (symmetric axis) in Fig. 5. It has been found in Fig. 6(a) that the gas mixture plasma was mainly balanced out with positive oxygen ion $\left(\mathrm{O}_{2}{ }^{+}\right), \mathrm{O}^{-}$and $e$. This result suggests that the $\mathrm{TEOS} / \mathrm{O}_{2} / \mathrm{Ar} / \mathrm{He}$ gas mixture plasma is an electronegative discharged plasma. Figure 6(b) shows the spatial distribution of example Si-containing neutral fragments generated in the plasma during the TEOS gas travels through the gap from the showerhead to the wafer. It was seen that the TEOS gas decomposed dramatically to other TEOS fragments. Among the TEOS fragments, $\mathrm{SiO}$ precursor is the dominant species near the wafer region.

Figure 7 illustrates the contours for various species in the plasma and Fig. 8 plots the time-averaged densities of various species and electron temperature $\left(T_{e}\right)$ in the $\operatorname{radius}(r)$ direction over the wafer surface. Interestingly, in the reactor, there seems to exist three regions in which the electronegativity differs from one another. As shown in Figs 8, electron density $\left(n_{e}\right)$ as well as the number densities of other species are radially uniform in region (Reg.) I, i.e. $r \leq 100 \mathrm{~mm}$. By contrast, in Reg. II, i.e. $r \geq 120 \mathrm{~mm}, T_{e}$ changed 
significantly, which resulted in the change of $n_{e}$ in this region. The change in $T_{e}$ and $n_{e}$ affects the other species that generated via the electron impact correspondingly. In Reg. I, the dominant species are $\mathrm{O}_{2}{ }^{+}$and $e$, whereas $\mathrm{O}_{2}{ }^{+}$and $\mathrm{O}^{-}$dominate over the others in Reg. II. This results suggest that the plasma in Reg. I is less electronegative than that in Reg. II. The observation of two regions of different plasmas is attributed to the effects of electric filed as will be described below. The Reg. III is the transition one between Regs. I and II.

Figure 9 shows a spatiotemporal electric field $(E F)$ strength (contours) and its vectors around the wafer edge. Figires $9(\mathrm{a})-(\mathrm{d})$ correspond to the plasma phases at $2 \pi f t=0, \pi / 4$, $\pi / 2$ and $3 \pi / 4$ in Eq. 1, respectively. For the sake of the simplicity, the vectors only correspond to the $E F$ strength smaller than $10^{4} \mathrm{~V} / \mathrm{m}$ are shown. As mentioned above, the wafer radius $r_{\text {wafer }}$ is geometrically smaller than the electrode radius $r_{\text {electr }}$ in Fig. 5. Under such condition, the $r$-component of the $E F$ is induced due to the discontinuity by the two different materials of wafer and dielectric stage. It has been found in Figs. 9 (a) and (d) that a strong $r$ - component of $E F$ appears at the wafer edge and circumferentially propagates. The inward-propagation of the $E F$ confined the plasma inside the Reg. I, and therefore the plasma density decreased in Reg. III as shown in Fig. 7 and 8. It was also seen that the $r$-component of the $E F$ becomes stronger and simultaneously spreads towards $Z$ direction around $120 \leq r \leq 150 \mathrm{~mm}$ at the phase of $3 \pi / 4$ as depicted in Fig. 9(d). In the 
region of $r>r_{\text {wafer }}$, on the other hand, since the absence of the wafer at the edge of the lower electrode, the plasma is directly exposed to the electrodes. As shown in Figs. 9(b) and (c) $Z$-component of the $E F$ becomes stronger, and therefore the plasma feels much greater $E F$ in Reg. II than in Reg. I, resulting in a densely populated region where $T_{e}$ is high and correspondingly reaction rate is large. Similar phenomenon was also observed in other literature [34].

Figure 10 shows the normalized deposition rate versus wafer radius, and the number densities of $\mathrm{O}, \mathrm{O}_{2}{ }^{+}$and $\mathrm{SiO}$ as well. It should be noted that the computed DR is in Reg. I about $100 \mathrm{~nm} / \mathrm{min}$, which is close to that observed in experiments under similar experimental conditions. Figure 10(a) shows the comparison of normalized DRs from the simulation work and experimental data. Since the experimental process conditions is slightly different from the simulation ones, the DRs were normalized in the comparison in order to qualitatively discuss the DR profiles. It was clearly seen in Fig. 10(a) that the computed DR is more radially uniform than that observed in the experiment. The experimental data appeared an obvious concave-convex shape in the deposited film thickness, which was not seen in the simulation. In experiment, the DR is uniform in $r \leq 100 \mathrm{~mm}$ region, slightly decreased at around $r=100 \mathrm{~mm}$, and increased at $r=120 \mathrm{~mm}$, suggesting that these changes in DR are due to the plasma characteristics in different regions, i.e. Regs. I, II and III in Fig. 8. As 
shown in Fig. 10(b), these results suggest a correlation that the higher $\mathrm{O}$ and/or $\mathrm{O}_{2}^{+}$ concentrations in the simulation, the larger DR is. The generation of $\mathrm{O}$ and $/ \mathrm{or}_{2}{ }^{+}$is contributed to the direct electron impact dissociations (e.g. $e+\mathrm{O}_{2} \rightarrow 0+0+e, e+$ $\left.\mathrm{O}_{2} \rightarrow \mathrm{O}_{2}^{+}+2 e\right)$ and increase in the $n_{e}$ as we discussed above.

However, in this current surface model, we missed the effects of ion species, such as $\mathrm{O}_{2}{ }^{+}$and $\mathrm{O}^{-}$, whose amount at the surface are nearly equivalent to the neutral oxygen atom. As mentioned earlier, the ion species neutralized at the surface when they hit the surface. Hence these ion species only contribute to the film deposition after they were neutralized, resulting in a difference type of their contributions other than a direct ion-induced deposition and its uniformity. From the data in Figs. 8 and 10, the ion species are likely to strongly affects the wafer uniformity, and one might speculate that the deposition rate and uniformity depends on the both neutral atomic and charged oxygen species. Such direct contributions of the ion species should be considered for developing a more accurate PECVD model and deferred to future study.

\section{Conclusions}

In this study, we have developed a computational model for $\mathrm{SiO}_{2} \mathrm{PECVD}$ process using TEOS $/ \mathrm{O}_{2} / \mathrm{Ar} / \mathrm{He}$ gas mixture with a careful description of chemistry model. The $\mathrm{TEOS} / \mathrm{O}_{2} / \mathrm{Ar} / \mathrm{He}$ plasma chemistry model consists of gas phase reaction model and surface 
reaction model. In the plasma chemistry model, we have 195 reactions in the gas phase reaction model and 25 reactions in the surface reaction model, involving 49 species of neutrals, ions and radials. In the gas phase reactions, we have described the 18 neutral dissociations in electron impact reactions. Decomposition reaction pathways for TEOS, including the neutral and ion species generated in the electron impact reactions, were also proposed in this study. In the surface reactions, we considered that $\mathrm{SiO}$ is the main precursor directly contributes to the film growth. The TEOS $/ \mathrm{O}_{2} / \mathrm{Ar} / \mathrm{He}$ plasma chemistry model was examined by $0 \mathrm{D}$ simulation with CHEMKIN Pro. We have also performed the $2 \mathrm{D}$ simulation with the same chemistry model as used in the $0 \mathrm{D}$ simulation. The simulation results have shown that $\mathrm{SiO}$ and $\mathrm{O}$ atom are the dominant species for obtaining a high deposition rate, and the deposition rate is proportional to the $\mathrm{O}$ atom density. In the $2 \mathrm{D}$ simulation, it was also found that effects of the electric field result in three regions with different plasma characteristics. The $2 \mathrm{D}$ simulation results have shown that the plasma becomes more electronegative at the edge of the wafer. In Reg. I, the dominant species that make the gas mixture plasma balanced out are $\mathrm{O}_{2}{ }^{+}, \mathrm{O}^{-}$and $e$, whereas in Reg. $\mathrm{II}_{2}{ }^{+}$and $\mathrm{O}^{-}$become dominant, suggesting that plasma in Reg. II is more electronegative than that in Reg. I. The observation of three regions that is affected by electric field suggest that uniformity is due to such different plasma characteristics. 
The results observed in this study have provided a further understanding of deposition mechanisms in a TEOS based PECVD process. We believe that the current chemistry model is able to qualitatively capture the physical phenomenon in the PECVD processes, but also requires a further improvement. The computational analysis in this study suggests that similar mechanism occur with an alternative gas which potentially has less cost problem in the similar PECVD process to TEOS.

\section{Acknowledgments}

The authors would like to acknowledge Peter L. G. Ventzek of Tokyo Electron America Inc. for helpful discussions. The authors also wish to thank Daisuke Oba, Takayuki Komiya and Yoshinori Morisada of Tokyo Electron Technology Solutions Ltd. for providing the experimental data. 


\section{References}

1. S. R. Kalidindi and S. B. Desu, J. Electrochem. Soc. 137, 624 (1990).

2. G. B. Raupp and T. S. Cale, Chem. Mater. 1, 207 (1989).

3. G. B. Raupp, T. S. Cale and H. P. W. Hey, J. Vac. Sci. Technol. B 10, 37 (1992).

4. P. J. Stout and M. J. Kushner, J. Vac. Sci. Technol. A 11, 2562 (1993).

5. M. Virmani, D. A. Levedakis, G. B. Raupp and T. S. Cale, J. Vac. Sci. Technol. A 14, 977 (1996).

6. A. Granier, C. Vallée, A. Goullet, K. Aumaille and G. Turban, J. Vac. Sci. Technol. A 17, 2470 (1999).

7. J. Holtgrave, K. Riehl, D. Abner and P. D. Haaland, Chem. Phys. Lett. 215, 548 (1993).

8. R. Basner, R. Foest, M. Schmidt, F. Sigeneger, P. Kurunczi, K. Becker and H. Deutsch, Int. J. Mass Spectrom. Ion Process. 153, 65(1996).

9. S. Kawaguchi, K. Takahashi, K. Satoh and H. Itoh, Plasma Sources Sci. Technol. 26, $054001(2017)$.

10. Y. Morikawa, Phys. Rev. B 63, 033405. (2001)

11. F. Muttaqien, H. Oshima, Y. Hamamoto, K. Inagaki, I. Hamada and Y. Morikawa, Chem. Comm. 53, 9222 (2017).

12. J. Holtgrave, K. Riehl, D. Abner, D. Haaland, Chem. Phys. Lett. 215, 548 (1993). 
13. M. E. Coltrin, P. Ho, H. K. Moffat, R. J. Buss, Thin Solid Films, 365, 251 (2000).

14. W. L. Morgan, C. Winstead and V. McKoy, J. Appl. Phys. 92, 1663 (2002).

15. A. D. Becke, J. Chem. Phys. 98, 5648 (1993).

16. A. D. McLean and G. S. Chandler, J. Chem. Phys. 72, 5639 (1980).

17. K. Raghavachari, J. S. Binkley, R. Seeger, and J. A. Pople, J. Chem. Phys. 72, 650 (1980).

18. O. K. Rice and H. C. Ramsperger, J. Am. Chem. Soc. 49, 1617 (1927).

19. L. S. Kassel, J. Phys. Chem. 32, 225 (1928).

20. J. I. Steinfeld, J. S. Francisco, and W. L. Hase, Chemical Kinetics and Dynamics (Tokyo Kagaku Doujin, Tokyo, 1995), Chap.11, [in Japanese].

21. S. Kawaguchi, H. Higuchi, H. Li, K. Denpoh, K. Takahashi and K. Satoh, submitted to Jpn. J. Appl. Phys.

22. K. Okimura and N. Maeda, J. Vac. Sci. Technol. A 16, 3157 (1998).

23. P. Ho, Chemical Reactions in TEOS/Ozone Chemical vapor Deposition, Sandia National Labrtories Reoport, SAND2000-0217, (2000).

24. Web [http://dpc.nifs.ac.jp/DB/IEEJ].

25. M. Hayashi, NIFS-DATA-72, Toki, Japan (2003).

26. Research committee of electron collision cross sections in discharge plasma: Low energy electron-ion dynamics and simulations, 691, 74 (1998). 
27. E. Crowell, L. L. Tedder, H. C. Cho, F. M. Cascarano and M. A. Logan, J. Vac. Sci. Technol. A 8, 1863 (1990).

28. M. A. Liberman and A. J. Lichtenberg, Principles of Plasma Discharges and Materials Processing, ed. John Wiley \& Sons, Inc., (New York, NY, 1994).

29. CHEMKIN-PRO 15131, Reaction Design: San Diego, (2013).

30. K. Denpoh, J. Phys. D: Appl. Phys. 42, 032003 (2009).

31. Web [www2b.biglobe.ne.jp/ denpoh/Software/SWARM/].

32. M. J. Frisch, G. W. Trucks, H. B. Schlegel, G. E. Scuseria, M. A. Robb, J. R. Cheeseman, G. Scalmani, V. Barone, B. Mennucci, G. A. Petersson, H. Nakatsuji, M. Caricato, X. Li, H. P. Hratchian, A. F. Izmaylov, J. Bloino, G. Zheng, J. L. Sonnenberg, M. Hada, M. Ehara, K. Toyota, R. Fukuda, J. Hasegawa, M. Ishida, T. Nakajima, Y. Honda, O. Kitao, H. Nakai, T. Vreven, J. A. Montgomery, Jr., J. E. Peralta, F. Ogliaro, M. Bearpark, J. J. Heyd, E. Brothers, K. N. Kudin, V. N. Staroverov, R. Kobayashi, J. Normand, K. Raghavachari, A. Rendell, J. C. Burant, S. S. Iyengar, J. Tomasi, M. Cossi, N. Rega, J. M. Millam, M. Klene, J. E. Knox, J. B. Cross, V. Bakken, C. Adamo, J. Jaramillo, R. Gomperts, R. E. Stratmann, O. Yazyev, A. J. Austin, R. Cammi, C. Pomelli, J. W. Ochterski, R. L. Martin, K. Morokuma, V. G. Zakrzewski, G. A. Voth, P. Salvador, J. J. Dannenberg, S. Dapprich, A. D. Daniels, Ö. Farkas, J. B. Foresman, J. V. Ortiz, J. 
Cioslowski and D. J. Fox, Gaussian 09, Revision E.01, Gaussian, Inc., Wallingford CT, (2009).

33. CFD R C 2003 CFD-ACE Module Manual (Huntsville: ESI US R\&D Inc).

34. H. J. Kim and H. J. Lee, Plasma Sources Sci. Technol. 25, 035006 (2016).

35. L. Pekker, Thin Solid Films 312, 341 (1998).

36. D. S. Stafford and M. J. Kushner, J. Appl. Phys. 96, 2451 (2004).

37. P. Dohnal, Proc. 21st Annual Conf. PartII, 18 (2012).

38. A. V. Vasenkov, X. Li, G. S. Oehrlein and M. J. Kushner, J. Vac. Sci. Technol. A 22, 511 (2004).

39. T. J. Sommerer and M. J. Kushner, J. Appl. Phys. 71, 1654 (1992). 


\section{Figure captions}

Fig. 1. (Color online) Branching ratios and electron collision cross section set for TEOS.

The lines of the branching ratios in Fig. 1(a) correspond to the neutral dissociation (ND) reactions in Table I. Electron collision cross sections for $18 \mathrm{ND}$ reactions are plotted in green lines in Fig. 1(b). Here $q_{\text {mom }}, q_{\text {non-dis-ex }}, q_{\mathrm{vib}}, q_{\mathrm{i}}, q_{\mathrm{n}}$ are elastic momentum transfer, non-dissociative electronic excitation, vibrational excitation, ionization and neutral dissociation, respectively.

Fig. 2. (Color online) Decomposition reaction paths of TEOS and TEOS fragments with an $\mathrm{O}$ atom. The large light orange, the large gray, the small red and the white spheres represent $\mathrm{Si}, \mathrm{C}, \mathrm{O}$ and $\mathrm{H}$ atoms, respectively. The arrows are just guide to the eyes. The molecular formula and corresponding atomic mass of each species are also labelled. The geometrical structures of all the molecules, i.e. both neutrals in Fig. 2(a) and ions in Fig. 2(b), are fully optimized based on the DFT calculations with Gaussian09 package.

Fig. 3. (Color online) Atomic configuration of the surface reaction model. The large light orange, the small red and the white spheres represent $\mathrm{Si}, \mathrm{O}$ and $\mathrm{H}$ atoms, respectively. The surface is saturated by hydroxyl group $(\mathrm{OH})$. The simulation was performed with periodic 
boundary conditions and the unit is surrounded by the black line box.

Fig. 4. (Color online) The computed decomposition rate of $\mathrm{SiO}_{2}$ film and number densities of $\mathrm{SiO}$ and $\mathrm{O}$ atoms from $0 \mathrm{D}$ simulation as a function of $\mathrm{rf}$ power.

Fig. 5. Schematic view of 2D simulation. The gap between upper (showerhead) and lower electrodes is $9.2 \mathrm{~mm}$. $V_{r f}$ of $100 \mathrm{~V}$ was applied to the upper electrode, and the lower electrode was grounded. The source frequency applied to the upper electrode is $13.56 \mathrm{MHz}$. The gray block on the right side represents a dielectric. The wafer was set on a stage which is colored in gray.

Fig. 6. (Color online) Spatial distribution of number densities for the various species from 2D simulation results. The plotted data in Fig. 6 was the data on the center line (symmetric axis) in Fig. 5.

Fig. 7. (Color online) Contour plots for number densities of $e, \mathrm{O}_{2}^{+}, \mathrm{O}^{-}, \mathrm{O}^{+}, \mathrm{Ar}^{+}$and $\mathrm{He}^{+}$ generated in the reactor with $\mathrm{TEOS} / \mathrm{O}_{2} / \mathrm{Ar} / \mathrm{He}$ gas mixture. 
Fig. 8. (Color online) Number densities of dominant charged species and electron temperature versus radius. The plotted data in Fig. 8 was the data on the wafer surface in Fig. 5.

Fig. 9. (Color online) Spatial distribution of electric field $(E F)$ near the wafer edge region $(r \geq 110 \mathrm{~mm}$ ) at $2 \pi f t$ in Eq. 1 are (a) 0 , (b) $\pi / 4$, (c) $\pi / 2$ and (d) $3 \pi / 4$, respectively. The vectors represent the strength of $E F$.

Fig. 10. (Color online) (a)Comparison of normalized deposition rates (DR) between computational and experimental results and (b)computed number densities of $\mathrm{SiO}, \mathrm{O}_{2}{ }^{+}$and $\mathrm{O}$ with respect to wafer radius. 


\section{Table captions}

Table. I. Dissociative reactions by the electron impact for TEOS. The geometric structures for all the species are fully optimized with quantum mechanical simulation. The activation energy $E$ for each neutral dissociation reaction was estimated in its DFT calculations. The dissociative ionization reactions are from Refs. 9 and 12. The values for the dissociative ionization reactions are taken from Ref. 12. Geometric structures for the products in ionization reactions are just speculations from DFT calculations of this work based on their stoichiometry in Ref. 12.

Table. II. Penning ionization, electron detachment, recombination, charge transfer, energy transfer, quench and other reactions, which does not involve TEOS or TEOS fragments, in the gas phase reaction in this study. Here $\mathrm{M}$ represents $\mathrm{O}$ or $\mathrm{O}_{2}$. The symbols of *, + and represent radical, positive ion and negative ion, respectively.

Table III. Atomic concentrations of a $\mathrm{SiO}_{2}$ film measured by Rutherford backscattering spectrometry. The film was prepared by PECVD and without annealing after film deposition.

Table IV. Simulation conditions used in $0 \mathrm{D}$ and 2D plasma simulations. 
Figures and Tables
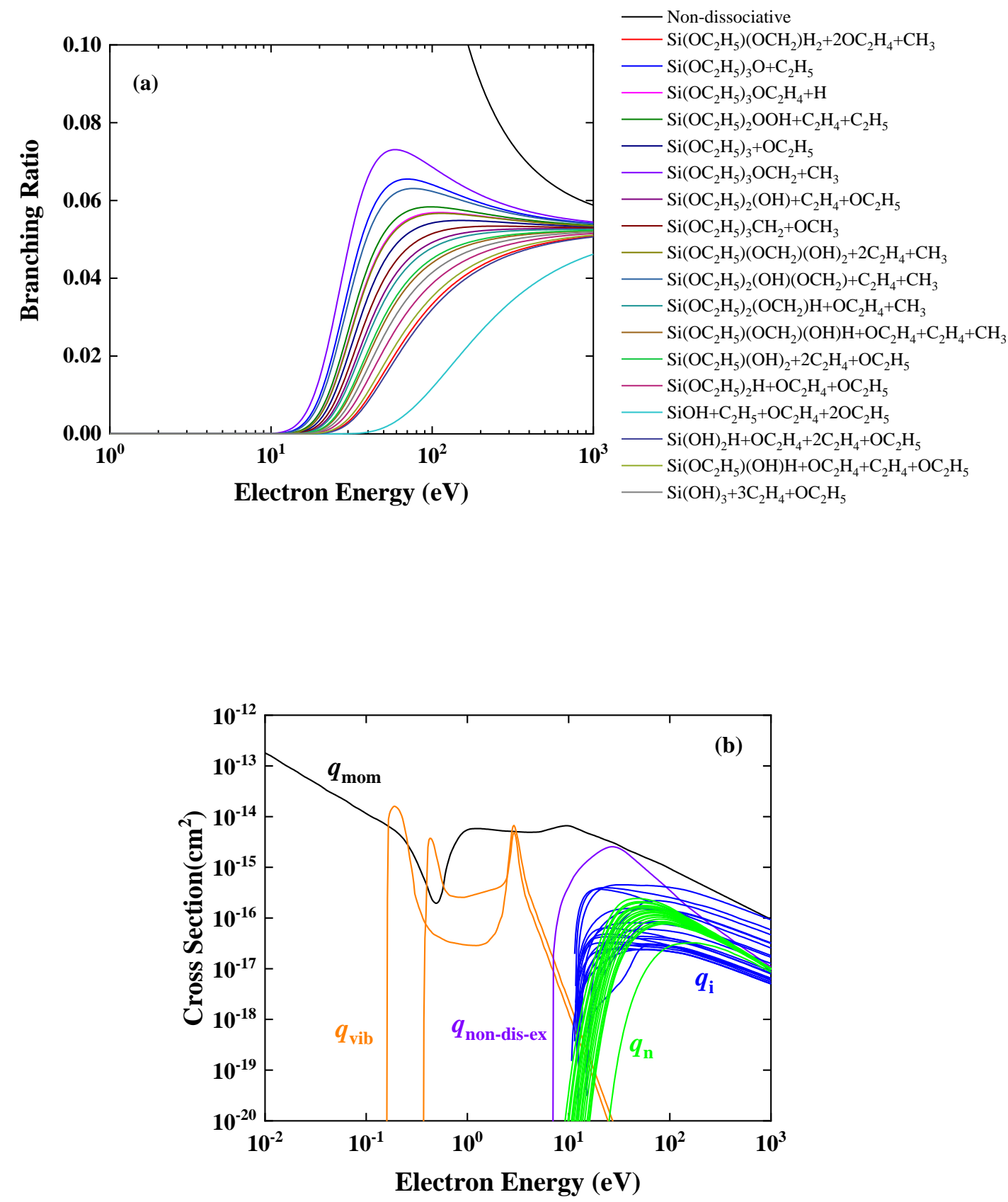

Figure 1. 
(a)
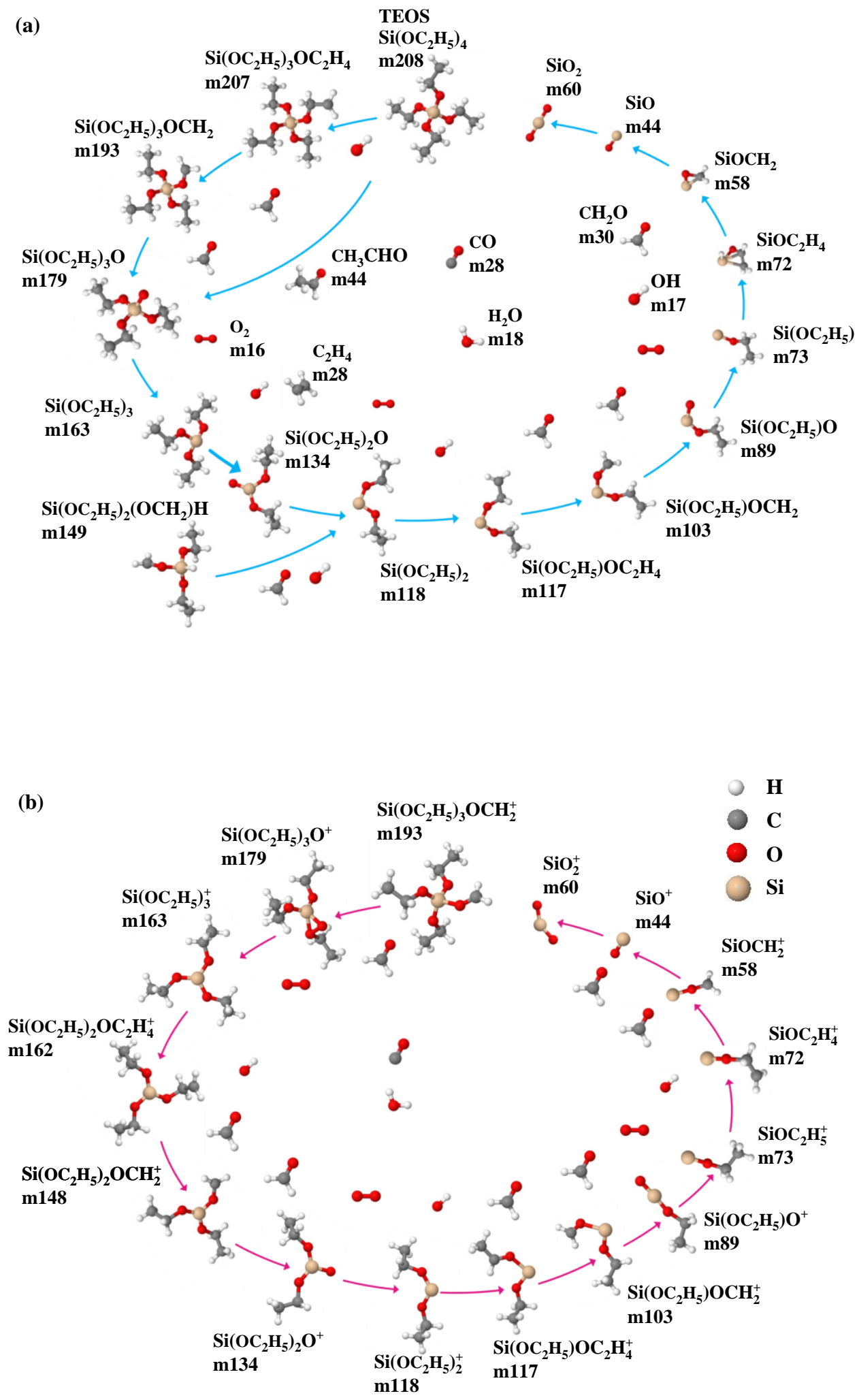

Figure 2. 


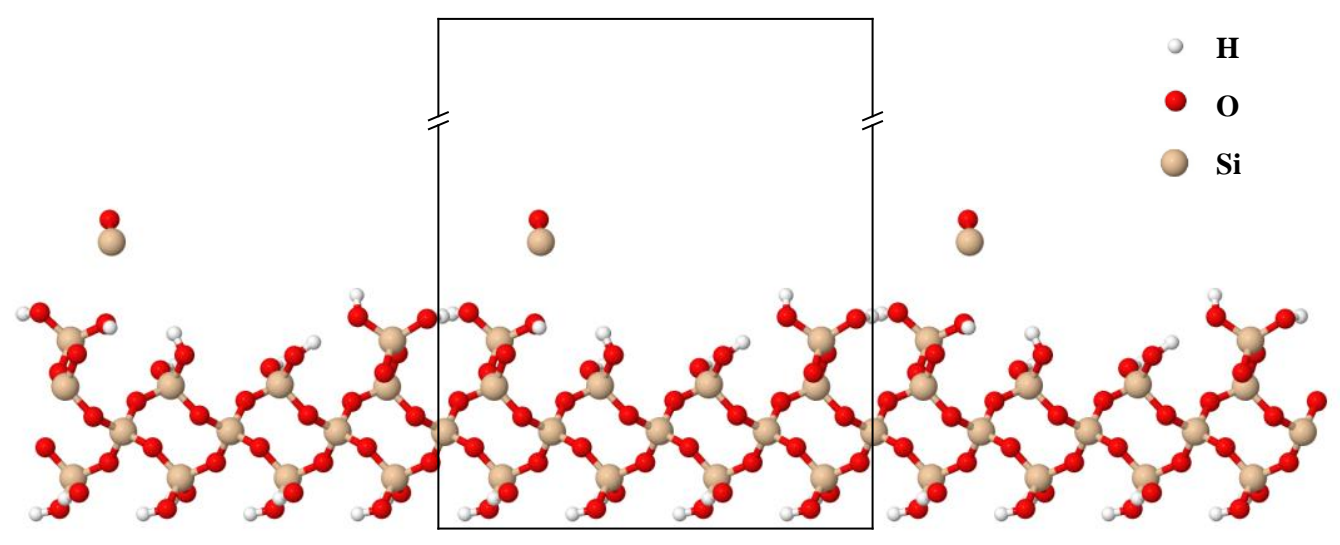

Figure 3. 


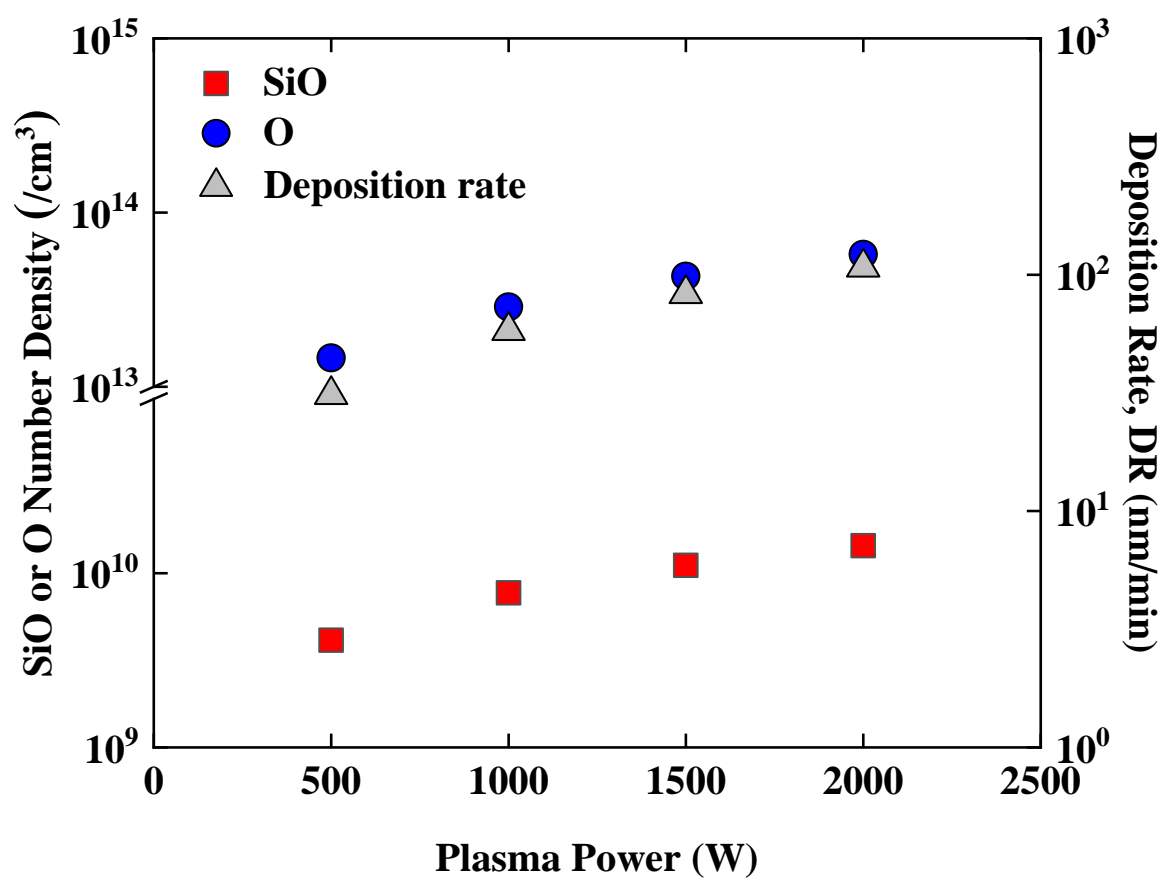

Figure 4. 


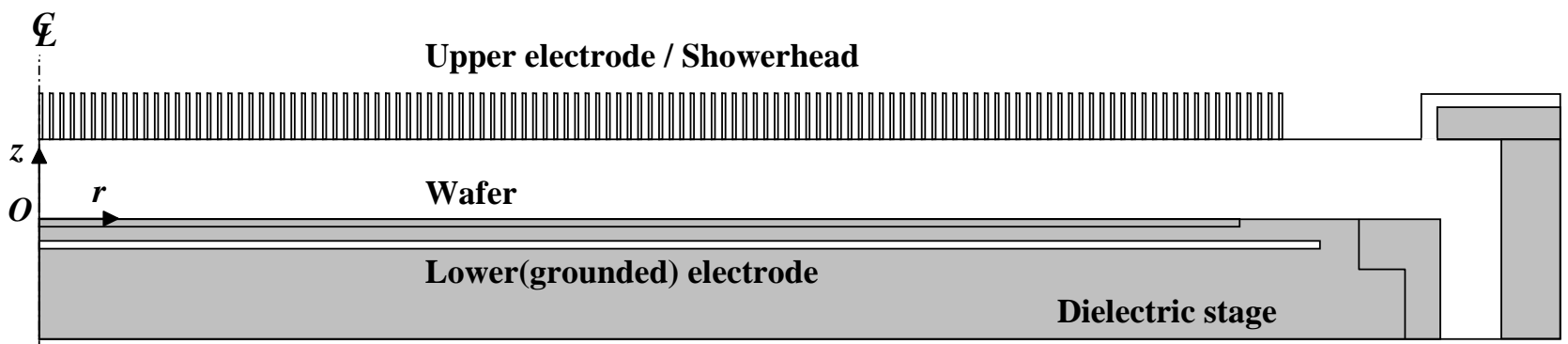

Figure 5. 

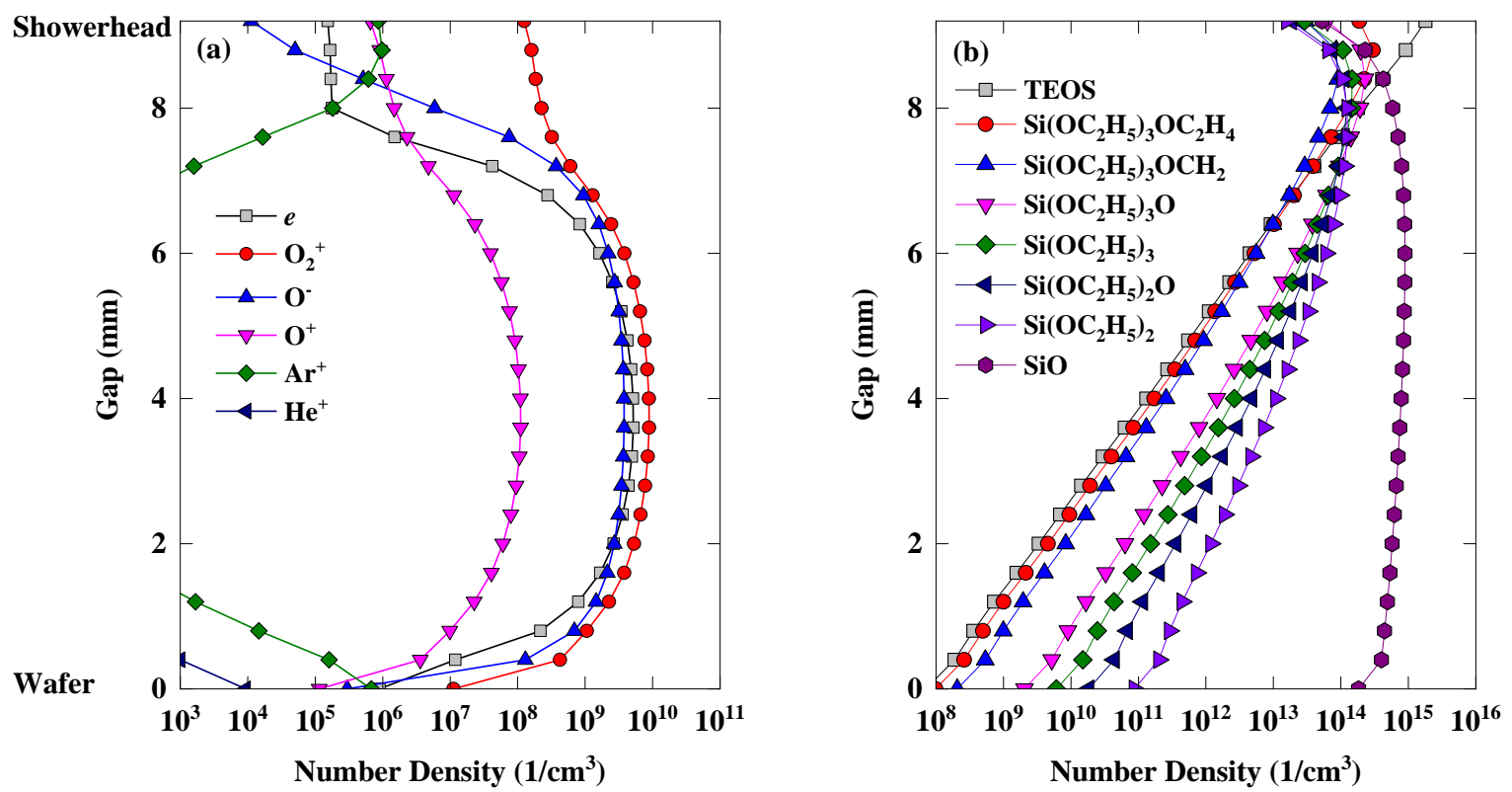

Figure 6. 

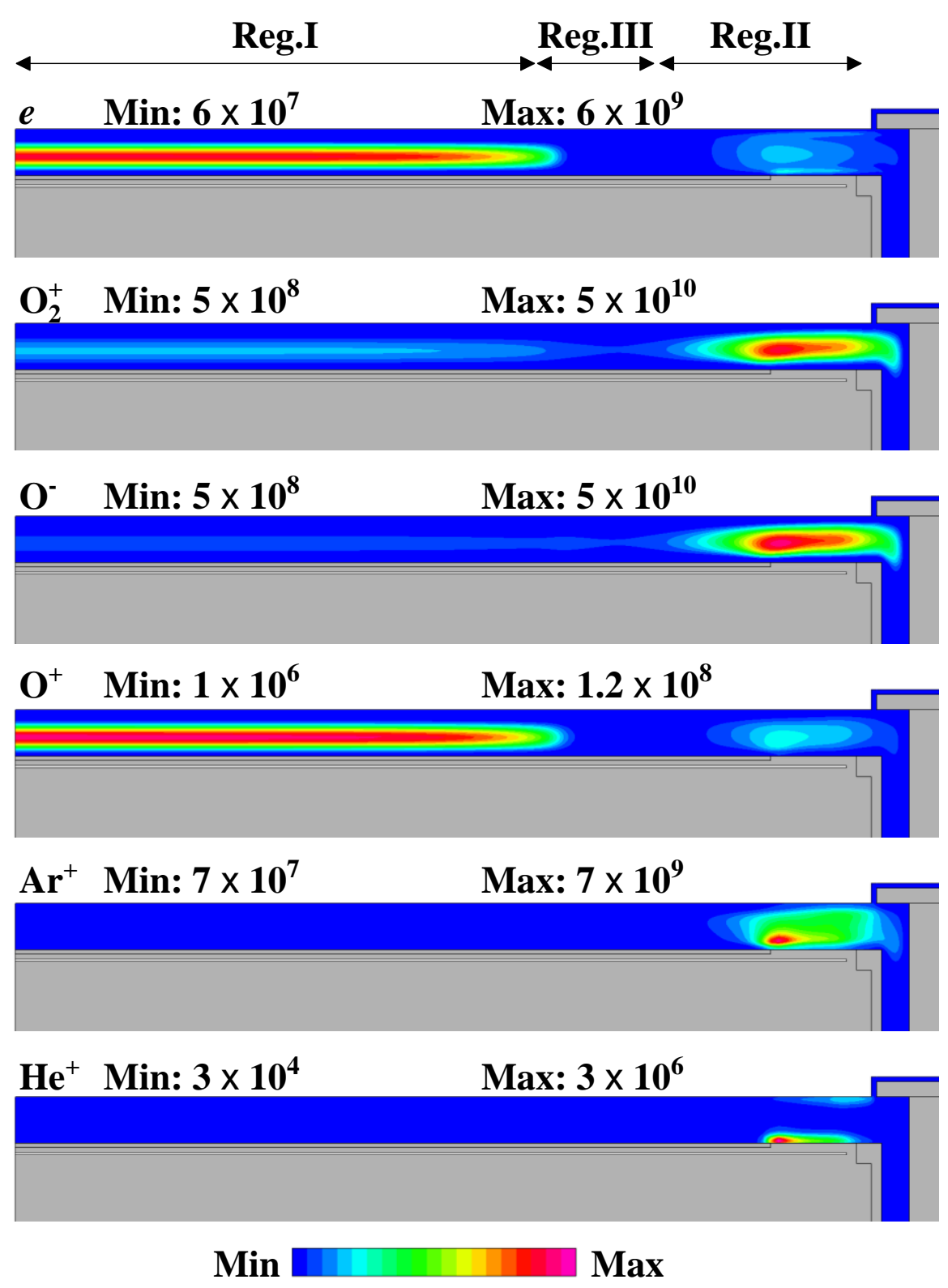

Figure 7. 


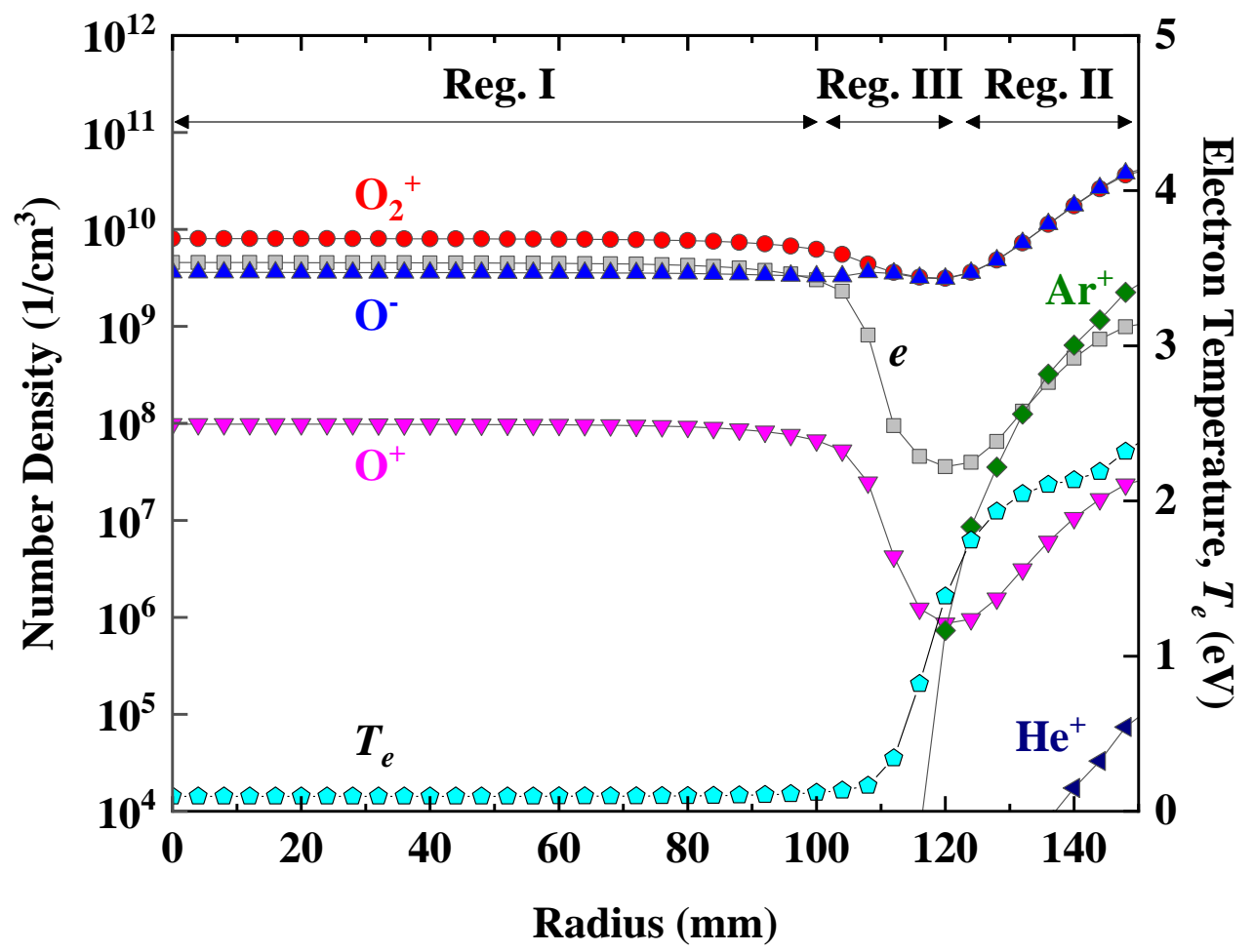

Figure 8. 
(a)

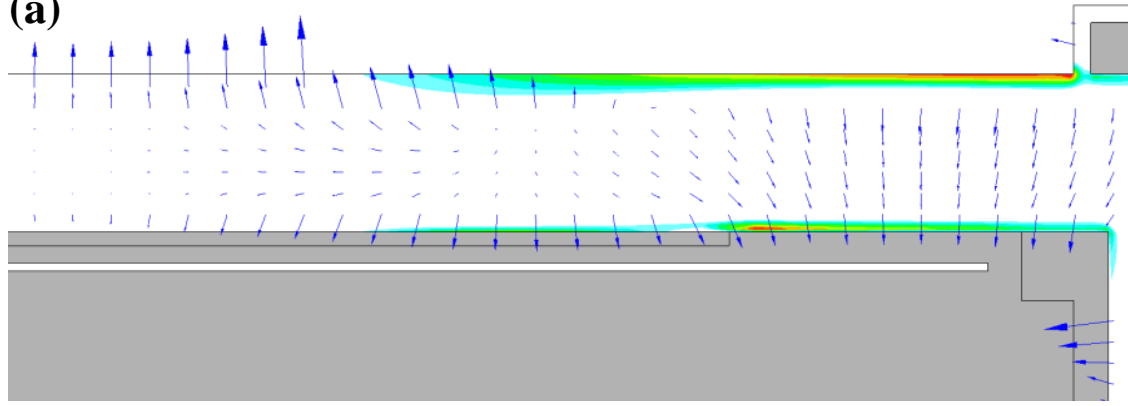

(b)
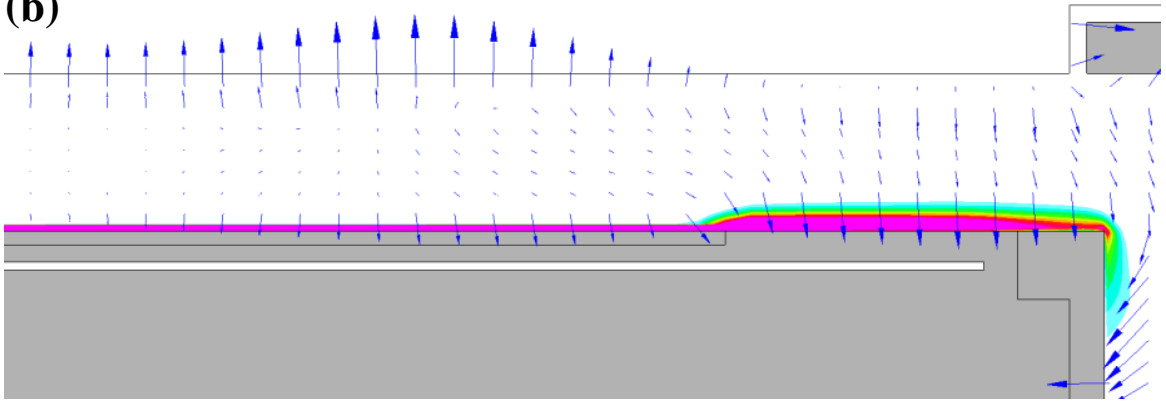

(c)
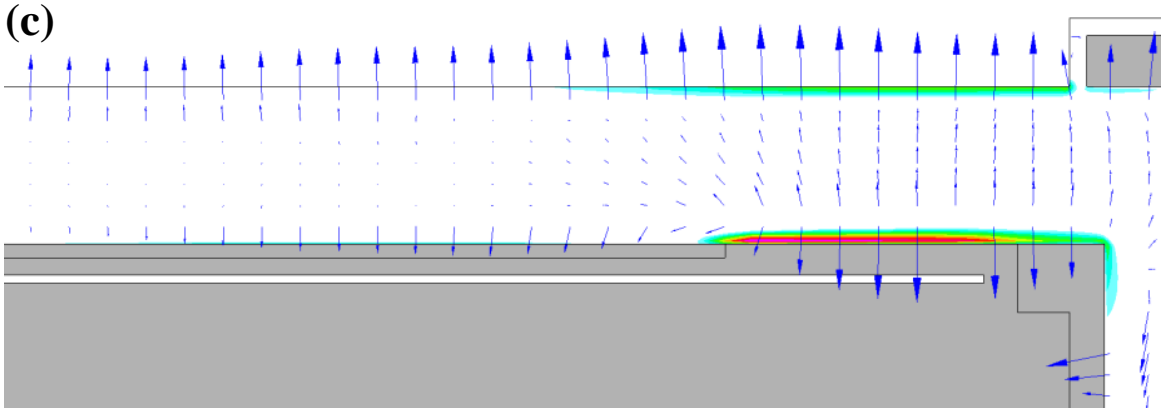

(d)

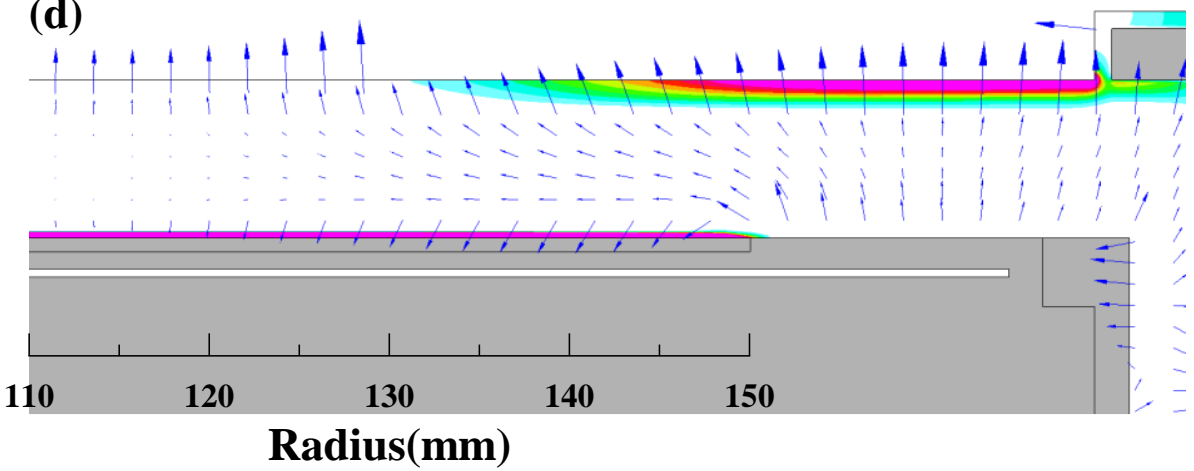

$\operatorname{Min}: 1 \times 10^{4} \longrightarrow$ Max:5x10

Figure 9. 

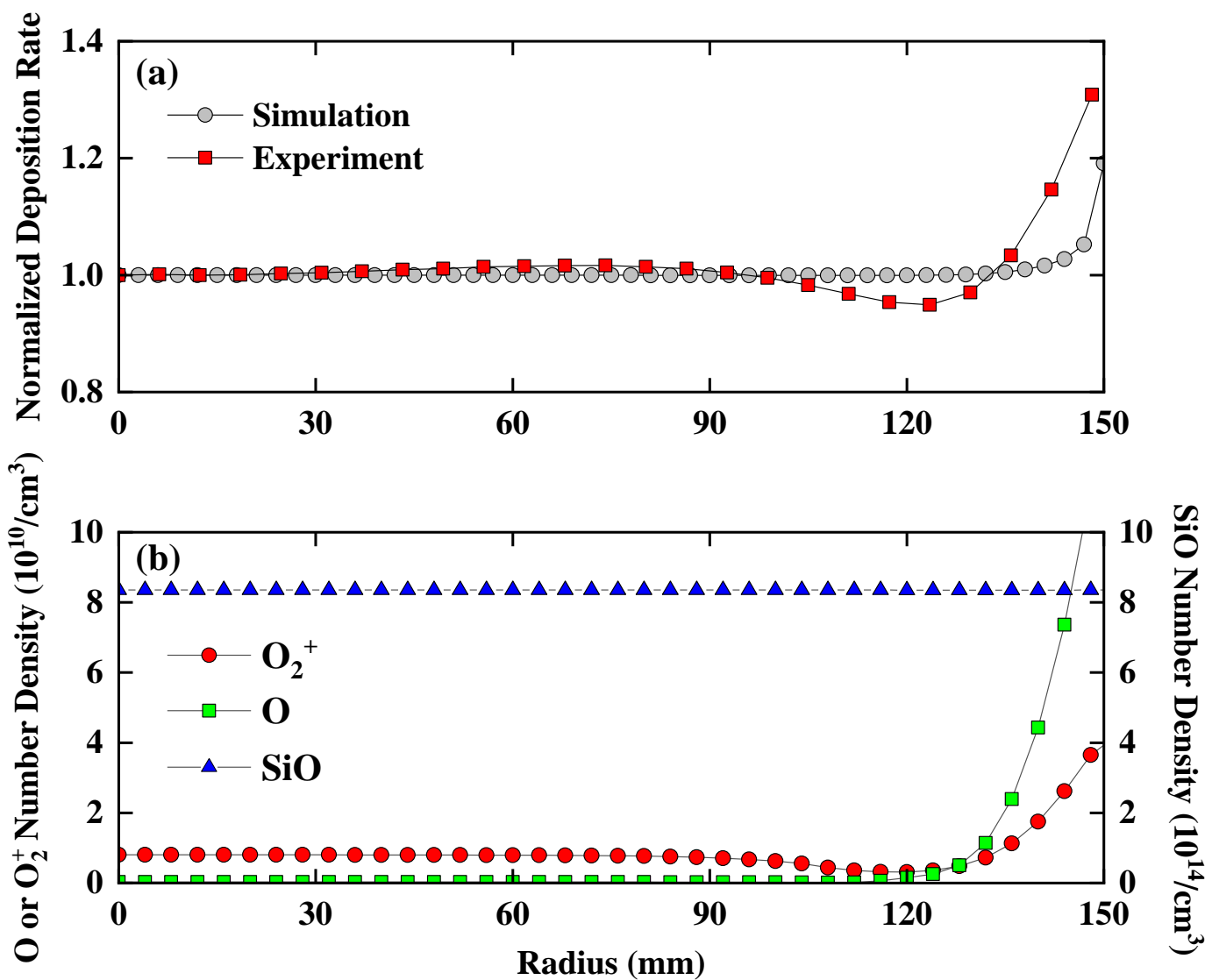

Figure 10. 
Table I

(a) Ionization $[9,12]$

\begin{tabular}{|c|c|c|c|}
\hline No. & Reactants & Products & $E, \mathrm{eV}$ \\
\hline 1 & $\mathrm{Si}\left(\mathrm{OC}_{2} \mathrm{H}_{5}\right)+e$ & $\mathrm{Si}\left(\mathrm{OC}_{2} \mathrm{H}_{5}\right)\left(\mathrm{OCH}_{2}\right) \mathrm{H}_{2}^{+}+\mathrm{OC}_{2} \mathrm{H}_{4}+\mathrm{OC}_{2} \mathrm{H}_{5}+\mathrm{CH}_{2}+2 e$ & 10.6 \\
\hline 2 & & $\mathrm{Si}\left(\mathrm{OC}_{2} \mathrm{H}_{5}\right)_{3} \mathrm{O}^{+}+\mathrm{C}_{2} \mathrm{H}_{4}+2 e$ & 11.3 \\
\hline 3 & & $\mathrm{Si}\left(\mathrm{OC}_{2} \mathrm{H}_{5}\right)_{3} \mathrm{OC}_{2} \mathrm{H}_{4}^{+}+\mathrm{H}+2 e$ & 11.4 \\
\hline 4 & & $\mathrm{Si}\left(\mathrm{OC}_{2} \mathrm{H}_{5}\right)_{3}+\mathrm{OC}_{2} \mathrm{H}_{5}^{+}+2 e$ & 11.6 \\
\hline 5 & & $\mathrm{Si}\left(\mathrm{OC}_{2} \mathrm{H}_{5}\right)_{4}^{+}+2 e$ & 11.6 \\
\hline 6 & & $\mathrm{Si}\left(\mathrm{OC}_{2} \mathrm{H}_{5}\right)_{3} \mathrm{O}(\mathrm{OH})^{+}+\mathrm{C}_{2} \mathrm{H}_{4}+\mathrm{C}_{2} \mathrm{H}_{5}+2 e$ & 11.6 \\
\hline 7 & & $\mathrm{Si}\left(\mathrm{OC}_{2} \mathrm{H}_{5}\right)_{3}^{+}+\mathrm{OC}_{2} \mathrm{H}_{5}+2 e$ & 11.6 \\
\hline 8 & & $\mathrm{Si}\left(\mathrm{OC}_{2} \mathrm{H}_{5}\right)_{3} \mathrm{OCH}_{2}^{+}+\mathrm{CH}_{3}+2 e$ & 11.7 \\
\hline 9 & & $\mathrm{Si}\left(\mathrm{OC}_{2} \mathrm{H}_{5}\right)_{2}(\mathrm{OH})^{+}+\mathrm{C}_{2} \mathrm{H}_{4}+\mathrm{OC}_{2} \mathrm{H}_{5}+2 e$ & 12.0 \\
\hline 10 & & $\mathrm{Si}\left(\mathrm{OC}_{2} \mathrm{H}_{5}\right)_{3} \mathrm{CH}_{2}+\mathrm{OCH}_{3}^{+}+2 e$ & 12.0 \\
\hline 11 & & $\mathrm{Si}\left(\mathrm{OC}_{2} \mathrm{H}_{5}\right)\left(\mathrm{OCH}_{2}\right)(\mathrm{OH})_{2}^{+}+2 \mathrm{C}_{2} \mathrm{H}_{4}+\mathrm{CH}_{3}+2 e$ & 12.2 \\
\hline 12 & & $\mathrm{Si}\left(\mathrm{OC}_{2} \mathrm{H}_{5}\right)_{2}\left(\mathrm{OCH}_{2}\right)(\mathrm{OH})^{+}+\mathrm{OC}_{2} \mathrm{H}_{4}+\mathrm{CH}_{3}+2 e$ & 12.2 \\
\hline 13 & & $\mathrm{Si}\left(\mathrm{OC}_{2} \mathrm{H}_{5}\right)_{2}\left(\mathrm{OCH}_{2}\right) \mathrm{H}^{+}+\mathrm{OC}_{2} \mathrm{H}_{4}+\mathrm{CH}_{3}+2 e$ & 12.2 \\
\hline 14 & & $\mathrm{Si}\left(\mathrm{OC}_{2} \mathrm{H}_{5}\right)\left(\mathrm{OCH}_{2}\right)(\mathrm{OH}) \mathrm{H}^{+}+\mathrm{OC}_{2} \mathrm{H}_{4}+\mathrm{C}_{2} \mathrm{H}_{4}+\mathrm{CH}_{3}+2 e$ & 12.3 \\
\hline 15 & & $\mathrm{Si}\left(\mathrm{OC}_{2} \mathrm{H}_{5}\right)(\mathrm{OH})_{2}^{+}+2 \mathrm{C}_{2} \mathrm{H}_{4}+\mathrm{OC}_{2} \mathrm{H}_{5}+2 e$ & 12.7 \\
\hline
\end{tabular}


(b) Neutral Dissociation

\begin{tabular}{|c|c|c|c|}
\hline No. & Reactants & Products & $E, \mathrm{eV}$ \\
\hline 1 & $\mathrm{Si}\left(\mathrm{OC}_{2} \mathrm{H}_{5}\right)_{4}+e$ & $\mathrm{Si}\left(\mathrm{OC}_{2} \mathrm{H}_{5}\right)\left(\mathrm{OCH}_{2}\right) \mathrm{H}_{2}+2 \mathrm{OC}_{2} \mathrm{H}_{4} \mathrm{O}+\mathrm{CH}_{3}+e$ & 6.5 \\
\hline 2 & & $\mathrm{Si}\left(\mathrm{OC}_{2} \mathrm{H}_{5}\right)_{3} \mathrm{O}+\mathrm{C}_{2} \mathrm{H}_{5}+e$ & 3.7 \\
\hline 3 & & $\mathrm{Si}\left(\mathrm{OC}_{2} \mathrm{H}_{5}\right)_{3} \mathrm{OC}_{2} \mathrm{H}_{4}+\mathrm{H}+e$ & 4.2 \\
\hline 4 & & $\mathrm{Si}\left(\mathrm{OC}_{2} \mathrm{H}_{5}\right)_{2} \mathrm{OOH}+\mathrm{C}_{2} \mathrm{H}_{4}+\mathrm{C}_{2} \mathrm{H}_{5}+e$ & 4.1 \\
\hline 5 & & $\mathrm{Si}\left(\mathrm{OC}_{2} \mathrm{H}_{5}\right)_{3}+\mathrm{OC}_{2} \mathrm{H}_{5}+e$ & 4.4 \\
\hline 6 & & $\mathrm{Si}\left(\mathrm{OC}_{2} \mathrm{H}_{5}\right)_{3} \mathrm{OCH}_{2}+\mathrm{CH}_{3}+e$ & 3.4 \\
\hline 7 & & $\mathrm{Si}\left(\mathrm{OC}_{2} \mathrm{H}_{5}\right)_{2}(\mathrm{OH})+\mathrm{C}_{2} \mathrm{H}_{4}+\mathrm{OC}_{2} \mathrm{H}_{5}+e$ & 4.9 \\
\hline 8 & & $\mathrm{Si}\left(\mathrm{OC}_{2} \mathrm{H}_{5}\right)_{3} \mathrm{CH}_{2}+\mathrm{OCH}_{3}+e$ & 4.7 \\
\hline 9 & & $\mathrm{Si}\left(\mathrm{OC}_{2} \mathrm{H}_{5}\right)\left(\mathrm{OCH}_{2}\right)(\mathrm{OH})_{2}+2 \mathrm{C}_{2} \mathrm{H}_{4}+\mathrm{CH}_{3}+e$ & 4.3 \\
\hline 10 & & $\mathrm{Si}\left(\mathrm{OC}_{2} \mathrm{H}_{5}\right)_{2}\left(\mathrm{OCH}_{2}\right)(\mathrm{OH})+\mathrm{C}_{2} \mathrm{H}_{4}+\mathrm{CH}_{3}+e$ & 3.8 \\
\hline 11 & & $\mathrm{Si}\left(\mathrm{OC}_{2} \mathrm{H}_{5}\right)_{2}\left(\mathrm{OCH}_{2}\right) \mathrm{H}+\mathrm{OC}_{2} \mathrm{H}_{4}+\mathrm{CH}_{3}+e$ & 5.0 \\
\hline 12 & & $\mathrm{Si}\left(\mathrm{OC}_{2} \mathrm{H}_{5}\right)\left(\mathrm{OCH}_{2}\right)(\mathrm{OH}) \mathrm{H}+\mathrm{OC}_{2} \mathrm{H}_{4}+\mathrm{C}_{2} \mathrm{H}_{4}+\mathrm{CH}_{3}+e$ & 5.3 \\
\hline 13 & & $\mathrm{Si}\left(\mathrm{OC}_{2} \mathrm{H}_{5}\right)(\mathrm{OH})_{2}+\mathrm{OC}_{2} \mathrm{H}_{5}+2 \mathrm{C}_{2} \mathrm{H}_{4}+e$ & 5.2 \\
\hline 14 & & $\mathrm{Si}\left(\mathrm{OC}_{2} \mathrm{H}_{5}\right)_{2} \mathrm{H}+\mathrm{OC}_{2} \mathrm{H}_{4}+\mathrm{OC}_{2} \mathrm{H}_{5}+e$ & 5.9 \\
\hline 15 & & $\mathrm{SiOH}+\mathrm{OC}_{2} \mathrm{H}_{4}+2 \mathrm{OC}_{2} \mathrm{H}_{5}+\mathrm{C}_{2} \mathrm{H}_{5}+e$ & 10.8 \\
\hline
\end{tabular}


Table II

\begin{tabular}{|c|c|c|c|c|}
\hline No. & Reactants & Products & Note & Reference \\
\hline 1 & $\mathrm{Ar}^{*}+\mathrm{Ar}^{*}$ & $\mathrm{Ar}^{+}+\mathrm{Ar}+e$ & Penning ionization (PI) & 35 \\
\hline 2 & $\mathrm{He}^{*}+\mathrm{He}^{*}$ & $\mathrm{He}^{+}+\mathrm{He}+e$ & PI & 36 \\
\hline 3 & $\mathrm{He}^{*}+\mathrm{Ar}$ & $\mathrm{Ar}^{+}+\mathrm{He}+e$ & PI & 37 \\
\hline 4 & $\mathrm{He}^{*}+\mathrm{O}_{2}$ & $\mathrm{O}_{2}^{+}+\mathrm{He}+e$ & PI & 36 \\
\hline 5 & $\mathrm{He}^{*}+\mathrm{O}$ & $\mathrm{O}^{+}+\mathrm{He}+e$ & PI & 36 \\
\hline 6 & $0^{-}+0$ & $\mathrm{O}_{2}+e$ & Electron detachment & 28 \\
\hline 7 & $\mathrm{Ar}^{+}+\mathrm{O}^{-}$ & $\mathrm{Ar}+\mathrm{O}$ & Recombination (RC) & 38 \\
\hline 8 & $\mathrm{He}^{+}+\mathrm{O}^{-}$ & $\mathrm{He}+\mathrm{O}$ & $\mathrm{RC}$ & 39 \\
\hline 9 & $\mathrm{O}^{-}+\mathrm{O}_{2}^{+}$ & $\mathrm{O}+\mathrm{O}_{2}$ & $\mathrm{RC}$ & 28 \\
\hline 10 & $\mathrm{O}^{-}+\mathrm{O}_{2}^{+}$ & 30 & $\mathrm{RC}$ & 28 \\
\hline 11 & $\mathrm{O}^{-}+\mathrm{O}^{+}$ & 20 & $\mathrm{RC}$ & 28 \\
\hline 12 & $\mathrm{Ar}^{+}+\mathrm{M}$ & $\mathrm{Ar}+\mathrm{M}^{+}$ & Charge transfer (CT) & 38 \\
\hline 13 & $\mathrm{He}^{+}+\mathrm{M}$ & $\mathrm{He}+\mathrm{M}^{+}$ & CT & 36 \\
\hline 14 & $\mathrm{He}^{+}+\mathrm{O}_{2}$ & $\mathrm{He}+\mathrm{O}+\mathrm{O}$ & $\mathrm{CT}$ & 36 \\
\hline 15 & $\mathrm{O}^{+}+\mathrm{M}$ & $\mathrm{O}+\mathrm{M}^{+}$ & CT & 28,38 \\
\hline
\end{tabular}




\begin{tabular}{|c|c|c|c|c|}
\hline 16 & $\mathrm{He}^{+}+\mathrm{Ar}$ & $\mathrm{He}+\mathrm{Ar}^{+}$ & $\mathrm{CT}$ & 37 \\
\hline 17 & $\mathrm{Ar}^{*}+0$ & $\mathrm{Ar}+\mathrm{O}^{*}$ & Energy transfer $(\mathrm{ET})$ & 38 \\
\hline 18 & $\mathrm{O}^{*}+\mathrm{O}_{2}$ & $\mathrm{O}+\mathrm{O}_{2}^{*}$ & ET & 28 \\
\hline 19 & $\mathrm{He}^{*}+\mathrm{He}$ & $2 \mathrm{He}$ & Quench (Q) & 39 \\
\hline 20 & $\mathrm{O}_{2}^{*}+\mathrm{M}$ & $\mathrm{O}_{2}+\mathrm{M}$ & Q & 28 \\
\hline 21 & $\mathrm{O}_{2}^{*}+\mathrm{O}_{2}^{*}$ & $\mathrm{O}_{2}+\mathrm{O}_{2}$ & $\mathrm{Q}$ & 38 \\
\hline 22 & $\mathrm{O}^{*}+\mathrm{M}$ & $\mathrm{O}+\mathrm{M}$ & $\mathrm{Q}$ & 28 \\
\hline 23 & $\mathrm{Ar}^{*}+\mathrm{O}_{2}$ & $\mathrm{Ar}+\mathrm{O}_{2}$ & Q & 38 \\
\hline 24 & $\mathrm{Ar}+\mathrm{O}_{2}^{*}$ & $\mathrm{Ar}+20$ & Q & 38 \\
\hline 25 & $\mathrm{Ar}+\mathrm{O}_{2}^{*}$ & $\mathrm{Ar}+\mathrm{O}_{2}$ & $\mathrm{Q}$ & 38 \\
\hline 26 & $\mathrm{Ar}+\mathrm{O}^{*}$ & $\mathrm{Ar}+0$ & $\mathrm{Q}$ & 38 \\
\hline
\end{tabular}


Table III

\begin{tabular}{llll}
\hline Atom type & $\mathrm{Si}$ & $\mathrm{H}$ & $\mathrm{O}$ \\
\hline Atomic concentration $(\%)$ & 32.2 & 2.2 & 65.6 \\
\hline
\end{tabular}


Table IV

Simulation conditions

\begin{tabular}{lll}
\hline Frequency & $\mathrm{MHz}$ & 13.56 \\
$V_{\mathrm{rf}}$ & $\mathrm{V}$ & 100 \\
Temperature & $\mathrm{K}$ & 823 \\
Pressure & Torr & 4 \\
Gap & $\mathrm{mm}$ & 9.2 \\
\hline Gas flow ratio & TEOS & 0.04 \\
& & 0.55 \\
& $\mathrm{O} 2$ & 0.27 \\
\hline & Ar & 0.14 \\
\hline
\end{tabular}

